\title{
DEVELOPMENT OF THE CONTENT AND FUNCTIONS OF A FIRM WITH THE ACCOUNT OF THE ECONOMIC DISEQUILIBRIUM CONDITIONS
}

\author{
Kabir Saubanov ${ }^{1}$ \\ Mikhail Nikolaev ${ }^{2}$
}

\begin{abstract}
The paper examines the actual problem which is a complex and contradictory process of origin, formation and development of a firm and its functions. It is shown that the structure of a firm, the features of its organization, the nature of the functions performed and the changes occurring therein have a great influence on the efficiency of management, on the properties and characteristics of economic systems. It is within its framework that a complex process of interaction between all factors of human life activity: historical, natural, cultural, economic, including the basic principles and types of long-term behavior of economic agents are formed. All that has been said undoubtedly confirms the relevance of the topic under research. However, despite the importance of solving these problems, up to the present
\end{abstract}

\footnotetext{
${ }^{1}$ Kazan Federal University mnikolae@yandex.ru. Tel: +7 (903) 3079656
}

${ }^{2}$ Russian University of Cooperation, Kazan Cooperation Institute (Branch). E-mail: time there is no single understanding of the concept "firm", nor a generally accepted view of its nature and functions. In the paper, all these issues are considered in relation to various stages of economic evolution and in the context of several main approaches: classical, institutional, evolutionary and behavioral, in which the concepts of the firm, its nature and functions are significantly different. The main directions of gradual changes in views on the institution of "firm" are shown: a consistent departure, and then a complete rejection of the principle of rationality, which was decisive at the stage of domination of the classical approach; weakening the importance of the theory of general equilibrium; creation of "company" models, first, describing its behavior in the real conditions of economic uncertainty and a 
disequilibrium environment, secondly, orienting in making decisions not for the best, but for an acceptable result.

Keywords: firm; institute of "firm"; market; the nature of a firm; economic transformation; economic disequilibrium.

\section{Introduction}

A company is one of the main links of the economic system, the transformation in which affects the efficiency of management, the properties and characteristics of the system as a whole. A single point of view on the causes of origin, the content of a firm, and its functions does not exist. Representations about its purpose changed significantly as social and economic relations and socio-cultural environment developed. At the same time, these views played an important role in the formation of a stable, fullfledged and effective institution of a firm that is able to successfully resist negative and crisis phenomena in the economy. Especially relevant is to ensure full compliance of the firm with the goals and directions of industrial policy, as well as the tasks of ensuring the competitiveness of the economic system.

Especially large changes in the content and functions of a firm take place during periods of economic transformation, as happened, for example, in the Russian Federation and other countries of Eastern Europe in their transition to the market economy. These changes were caused by numerous violations of the previously established links between individual elements of the economic system, including the most significant of them which determine the type of economic disequilibrium that has developed at the moment. These include the interaction between organizational forms of production, the relationship between personal and material factors, the regional and branch structure of the economy, and the structure of investment.

These violations are inevitably accompanied by changes in the position of a firm in the system of economic relations and its functions, as well as by the growth of all types of their costs: production, transaction, and dissipative. This, in turn, complicates the functioning of the economic system due to the impossibility of timely receipt of 
undistorted management and price signals into its subsystems and to individual economic entities.

The result of changes in the transforming economy is the redistribution of product releases between individual firms and companies. In this case, unlike the conditions of the usual market system, where it would have occurred in favor of the most effective actors, in a transforming economy everything takes place in another way. This circumstance makes it necessary to investigate the development of the concept "firm" content and functions of a firm, taking into account economic disequilibrium.

\section{Methods}

The following methods were used by authors in the work:

1) Historical, in accordance with which the content and functions of a firm were examined at various stages of their economic evolution, which made it possible to trace the temporal sequence and features of the emergence and development of their main elements and forms;
78

2) Comparative analysis method, through the prism of which the features of the concept "firm" content and functions of a firm were analyzed in the context of economic transformation and the accompanying pronounced economic disequilibrium;

3) Abstract-logical method, which is the main tool of economic modeling and scientific analysis, that made it possible to clarify the general scheme of the evolution of the institution of firm.

\section{Results and discussion}

One of the first attempts to understand the causes and conditions of origin of a firm, the variety of their sizes and types belongs to A. Smith, who identified the development of trade as such, as well as the scale of demand. A firm seemed to him as a way of production, which provides technical progress and an increase in labor productivity, illustrating this statement using the example of a pin factory [1].

In principle, A. Smith believed that a firm emerges and operates in a competitive market environment, which allows it to find and use equilibrium prices. Although competition was 
considered by him only as perfect one, and according to him, any role of the state in regulating the activities of firms should be completely denied. In fact, this was the principle "the lesser is the state influence, the better". A. Smith believed that the purpose of a firm is achievement of maximum efficiency of management, what corresponds to a strictly rational type of behavior of economic entities.

Smith's approach was later developed in the works of A. Marshall, J. Robinson, J. Schumpeter, and others.

Thus, A. Marshall supplemented and developed the idea of a firm as an organization, one of which functions is to ensure economies of scale, and thus he explained the formation of large economic structures. A. Marshall approached to the problem of formation of an equilibrium price in a different way. $\mathrm{He}$ showed that equilibrium is not a frozen, static state, but only a moment in a continuous development, which is both the final stage in the process of adaptation to changed conditions, and the starting state for a new process. In addition, A. Marshall essentially considered for the first time the interaction between firms in conditions of disequilibrium, using a special method for this purpose. $\mathrm{He}$ introduced the concepts of short-term and long-term periods and showed that the transition from one state of equilibrium to another is not instantaneous, but only through successive discontinuous iterations [2, 3]. This allowed A. Marshall firstly to look at the problem of the general economic equilibrium developed by $\mathrm{L}$. Valras, according to whom it should be considered unattainable. Secondly, to show that after a violation of an equilibrium state, the economic system can never again come to a new state which is the same as the previous one. And thus, A. Marshall has rejected the main thesis of the theory that economic evolution is an endless process of successive movement from one state of equilibrium to another. This state proved to be an exception to the rule rather than a stable state to which the market mechanism automatically leads.

A significant contribution to the improvement of the theory of a firm was made by J. Robinson. Considering the behavior of firms and the development of their functions under conditions of imperfect competition, and in fact in conditions of disequilibrium, he revealed 
new characteristics and factors of their behavior, for example, competition between manufacturers of differentiated products, price discrimination, etc. J. Robinson also drew attention to the possibility of a multiplicity of equilibrium states, showing that the market system functions in reality in more complex way than it was previously thought [4].

New provisions concerning the theory of a firm were proposed by $\mathrm{J}$. Schumpeter, who developed the theory of an entrepreneurial firm, which he understood as a special economic agent not aimed at maximizing profit or utility, as opposed to other concepts, but at forming strategic advantages in competition [5].

A new approach to the analysis of the content and functions of a firm was proposed by R. Coase, who used as the theoretical basis not the theory of general equilibrium, but the institutional concept, according to which a firm is no longer an integral organic element of the market, but, on the contrary, contrasted to it being a domestic production opposing to an external one. According to R. Coase, who viewed a firm as a system of relations, where the resources are completely dependent on the entrepreneur, its formation is associated with special transaction costs, and a firm itself is created in order to minimize them.

In addition, on the basis of the institutional approach, it was found that although a firm is created to minimize transaction costs, they are never completely destroyed because of the asymmetry of information. This means that one can judge the degree of economic disequilibrium by their magnitude.

A new and important step in deepening the understanding of a firm and its functions was made within the institutional framework by M. Jensen, W. Mekling and especially O. Williamson, who presented a firm as a set of long-term agreements or a "network of contracts" between economic agents specifying rights and obligations of parties [7]. According to this point of view, if the contracts were always perfect, that is, they could provide for any possible complications in relations between agents, a firm would not be needed. But since such contracts are not possible in principle, they all do not exclude opportunistic behavior of 
partners; hence the understanding of a firm arises as a network of such longterm contracts each of which is best suited to the specifics of a particular relevant transaction. The functions of a firm are presented here as an opportunity to choose such an optimal contract form that ensures maximum savings on transaction costs.

Another important step in developing an understanding of a company operating under conditions of a disequilibrium environment was made within the framework of evolutionary and behavioral theories, where the very understanding of a firm and its functions is fundamentally different from traditional ones.

So, in the first of them a firm is regarded as an almost complete analogue of a living organism, which continuously develops reacting to any changes in the external environment and, in turn, changing the rules of its behavior and thereby achieving effective results [8]. R. Nelson and S. Winter created a number of models describing the reaction of firms to changes occurring in the environment, for example, to the growth of investment, to rising prices, to structural and technological shifts in other industries. With the help of these models, they showed that such a reaction is really a reciprocal change by firms of the principles and norms of their behavior that were formed earlier on the basis of accumulated skills and techniques. These principles and norms they called routines, highlighting several of their types: those managing of shortterm behavior; those managing of longterm behavior; and those determining the principles of changing other routines of a lower order or search routines.

Upon that, the main task of a firm is to find a structure of those routines, in which their compliance with external conditions would be maximum. From this not only the effectiveness of their activities, but often the survival of a firm in a competitive struggle directly depends.

It follows from the foregoing that the process of the evolution of firms can be considered and represented as a continuous and consistent change in their behavioral characteristics or routines in interaction with the external environment. Schematically this can be represented as follows (Fig. 1): 


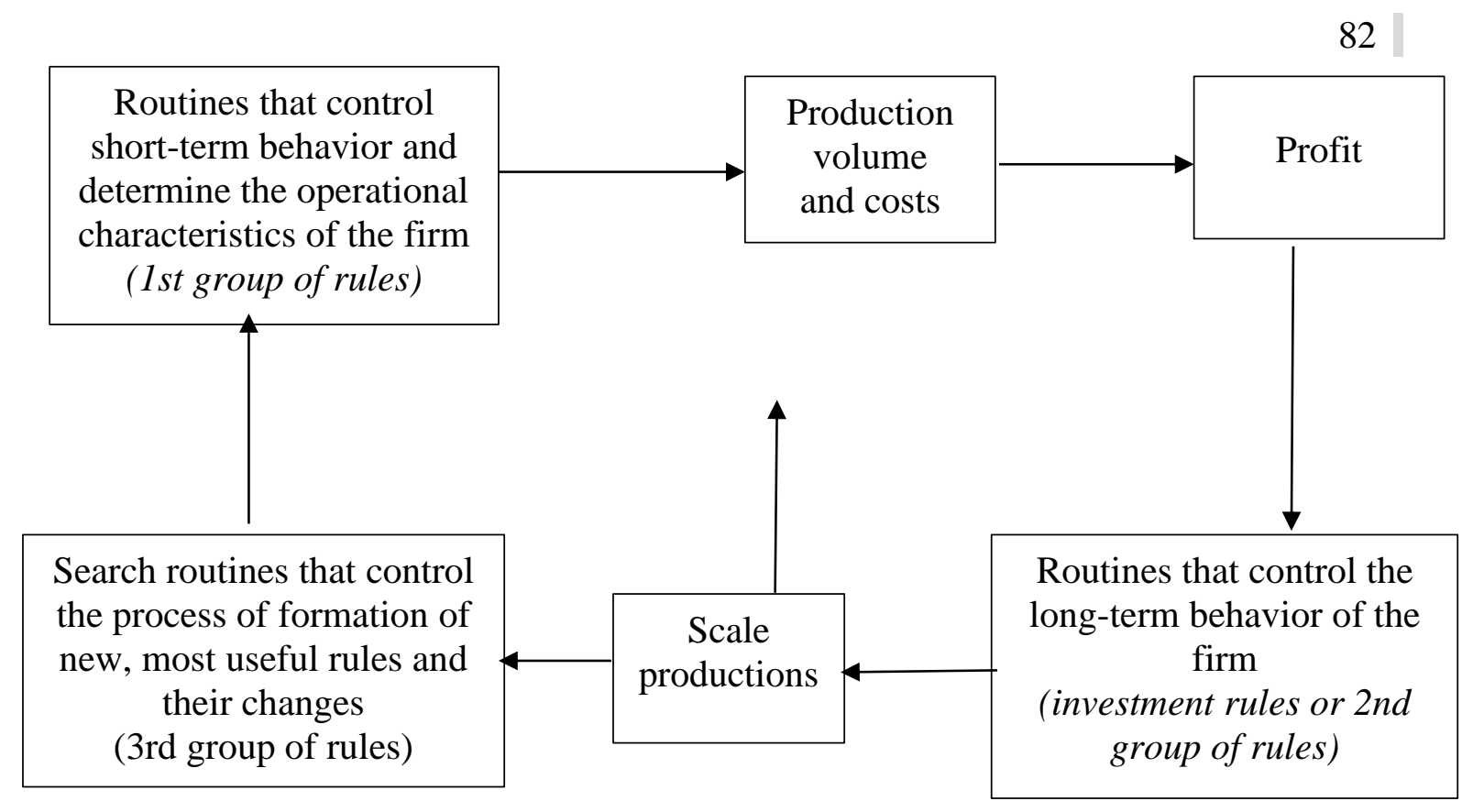

Fig.1. The evolution of a company from the standpoint of evolutionary theory

In the figure, we see that the routines that govern the short-term behavior of a firm determine the volume of output and costs. Taking into account the conditions of demand, supply and prices, this volume determines the amount of profit. The level of profit through another set of routines that control long-term behavior, i.e. with the help of investment rules, set the scale of production. The latter, in turn, determining the level of output and costs, affects these characteristics of a firm through a third set of routines aimed at finding the most useful rules and rules. Thus, the development of a firm is carried out through the process of continuous interaction, search and selection of routines and their adaptation to the constantly changing environmental conditions.

The given model of firm evolution differs radically from models based on the concept of general equilibrium, including due to complete lack of even the concept of maximizing efficiency. According to its ideas, the maximization of results does not occur at all in the process of evolution, but simply the search for the best option of management from all possible ones applicable only to these specific conditions. This option is usually far from the equilibrium and optimal. This 


\section{Periódico do Núcleo de Estudos e Pesquisas sobre Gênero e Direito Centro de Ciências Jurídicas - Universidade Federal da Paraíba V. 8 - No 04 - Ano 2019 - Special Edition ISSN | 2179-7137 | http://periodicos.ufpb.br/ojs2/index.php/ged/index}

approach to the evolution problems made it possible to take a completely new look at the established concepts and categories of traditional economic theory, and in essence opened up for the research and analysis in general not previously considered problems.

It should be noted that evolutionary selection illustrated by the example of only individual firms, is also implemented in economic systems of a more complex level of regions, industries, and the economy as a whole. However, here, for example, at the sectoral level, it consists not only in selecting the most useful routines for a firm, but also in the formation of new ones through the gradual extraction of them from a set of repetitive, analogous situations, and, in addition, the selection of firms themselves, the result of which is change in the industry structure. The process of development and selection is endless, and therefore it cannot be asserted that at some point the best industry structure was established, the most sophisticated routines were selected or the most effective firms were selected.

Thus, we see that with regard to the industry, as with the individual firm, from the point of view of evolutionary theory, too, it makes no sense to talk about any maximization of efficiency. It is only possible to find the best solution possible in the given circumstances.

The ideas of the evolutionary theory are echoed by the views of behavioral theory, where research and analysis of a real decision-making process taking place in households, firms and organizations are also at the forefront, and with this in mind a generalized new model of behavior of economic agents in a disequilibrium environment is constructed $[9 ; 10]$.

Among those basic provisions, there is an assertion that the decisions made by business entities are not based on the principle of rationality. In fact, they obey the generally accepted rules and conventions. An economic agent, unlike neoclassical notions, seeks not to maximize utility or profit, but to find a satisfactory option for it and when the first more or less acceptable result is reached, the search for new options ceases.

The acceptability or nonacceptability of the option is determined only by the subject itself, and is related to its level of claims, which correspond 
to its personal perceptions of what it should and can count on. If the result of economic activity is negative, then the level of personal claims is reduced, since the subject begins to treat its capabilities more critically. If the result is successful, then the level of claims is increased, and a new and higher goal is put in this case. Strictly speaking, the considered model of behavior is based on a personal intuition of the head of the firm and does not allow making reliable unambiguous predictions. And nevertheless, it is closer to the real decision-making process in comparison with the concept of equilibrium. It is also confirmed by economic practice, which provides many relevant testimonies. Following the rules a firm makes only a satisfactory choice, because in the conditions of uncertainty of the disequilibrium environment, it is still impossible to calculate everything in advance, it often gets better results than in cases of attempts to optimize firm's activity. Most firms tend to prefer to adhere to these same rules, even when a deviation from their original position might be more beneficial than upon compliance with it.

\section{Summary}

On the basis of the study, we can draw some conclusions:

1. A firm which is an independent primary economic link, has, as its functions, a complex content that continuously develops in time and reflects in itself all the numerous changes that are happening objectively in economic systems in the course of their evolution. Therefore, it cannot be fully described by the means of any one approach or by one model.

2. Each of the approaches, theories and concepts that in their own way define the essence and content of firms and explain their behavior and functions, has its strictly limited scope depending on the conditions and circumstances in which firms operate. Thus, situations close to equilibrium can be described with sufficient reliability even today by the production function, and situations characterized by a high degree of uncertainty and incompleteness of information are models of institutional, behavioral or evolutionary approaches.

3. The general trend in the development of the theory of a firm and its analytical tools is for today the 
growing interest in the apparatus of evolutionary and behavioral theory that are more adequate to today's economic realities.

\section{Conclusions}

In conclusion, we note that the analysis of evolutionary changes in the content and functions of a firm, their description, modeling and forecasting of development are most difficult to apply to a transforming economy where different types of economic disequilibrium collide simultaneously, and firms interact under conditions of transition from one of them to another, being simultaneously influenced by restrictions of a different nature. Therefore, it is impossible to satisfactorily describe their behavior using a single model. This imposes particularly stringent requirements on the analysis of the problem of the formation and development of the modern institute of the company in transformational systems. It should be implemented on the basis of an integrated system approach, taking into account the positive experience of other countries.

\section{Acknowledgments}

The work is carried out according to the Russian Government's Program of Competitive Growth of Kazan Federal University.

\section{Bibliography}

Adam Smith. An Inquiry into the Nature and Causes of the Wealth of Nations, Produced by Colin Muir, and David Widger, 2013, 985 p.

Marshall Alfred.Principles of Economics 8th Ed. - Palgrave Macmillan, 2013.- xxviii + 731 p.

Doroshenko M.E. Analysis of disequilibrium states and processes in macroeconomic models. - M: TEIS, 2000. - 206p.

Robinson Joan. The Economics of Imperfect Competition. London: Macmillan, 1933.

Schumpeter J.A. History of Economic Analysis. NY: Oxford University, 1954. 
Coase R.H. The firm, the Market, and the

Law. - University of Chicago Press, 2012. -226 p.

Williamson O.E. The Economic Institutions of Capitalism: Firms, Markets, Relational Contracting. - New York: The Free Press, 1985.

Nelson R., Winter S. An Evolutionary Theory of Economic Change.

Cambridge, Mass.: Harvard Univ. Press, 1982.

Herbert A. Simon.Theories of DecisionMaking in Economics and Behavioral Science. - The American Economic Review, Vol. 49, No. 3. (Jun., 1959), pp. 253-283.

Leibenstein H. Beyond the Economic Men. Cambridge (Mass), 1976. - 297p 